\title{
Clinical and epidemiological aspects of methylmercury poisoning
}

\author{
FARHAN BAKIR* \\ M.B.Ch.B., M.S., F.R.C.P.E., F.A.C.P. \\ S. TIKRITI \\ M.B.Ch.B., M.Sc.
}

\author{
H. Rustam \\ M.B.Ch.B., D.P.M. \\ S.F. Al-Damluji \\ M.B.Ch.B., M.D., F.R.C.P.L.
}

\author{
H. SHIHRISTANI \\ B.Sc., M.Sc., Ph.D.
}

\author{
Medical College and Medical City, Baghdad, Iraq
}

\begin{abstract}
Summary
An opportunity to study the effects of methylmercury poisoning in humans was provided by the large outbreak in Iraq in 1971-2. In adults, poisoning resulted from the ingestion of home-made bread prepared from methylmercury-treated seed grain and there was a highly significant correlation between the amount of bread ingested and blood mercury levels. Poisoning in infants resulted either from prior exposure in utero or from suckling or both. Blood mercury levels were higher in infants and children than in adults.

There was no increased incidence of congenital defects. Symptoms and signs of poisoning and histopathological changes were mainly confined to the CNS. Symptoms developed, on average, 1-2 months after exposure. In children there was mental retardation with delayed onset of speech and impaired motor, sensory and autonomic function. Severely affected children were blind and deaf. In adults, the clinical picture could be classified as 1 , mild (mainly of sensory symptoms) 2, moderate (sensory symptoms accompanied by cerebellar signs) and 3, severe (gross ataxia with marked visual and hearing loss which, in some cases, progressed to akinetic mutism followed by coma). Grades 1 and 2 carried a better prognosis than grade 3.

Interference with transmission at the myoneural junction was found in $14 \%$ of patients studied. There was no evidence of peripheral nerve involvement per se and sensory symptoms may be of central origin.

The clinical differences between the Iraqi and

* Reprint requests to Dr Bakir.
\end{abstract}

Japanese outbreaks may be a result, in part at least, of the severe, prolonged and continuous exposure which occurred in the latter outbreak. Improvement was observed among the mild and moderate group. Treatment with chelating agents, thiol resin, haemodialysls and exchange transfusion lowered blood mercury concentrations but produced no convincing clinical benefit. To be effective, treatment may need to be instituted soon after exposure.

\section{Introduction}

In the winter of 1971-72, an outbreak of methylmercury poisoning took place in the rural areas of Iraq. Following several years of disappointing crop yields, large quantities of seed grain were imported for planting in the autumn of 1971. The grain was treated with mercury compounds to prevent infection from various plant fungal diseases and thereby increase crop yield. The treated seed grain was distributed to farmers in the 3 main cereal growing areas in the south, central and northern regions of Iraq. Unfortunately, many of the farming families consumed home-made bread prepared from treated wheat (Bakir et al., 1973).

This outbreak took place at a time when worldwide interest in methylmercury poisoning had been aroused by the outbreaks in Japan by the discovery that mercury was methylated in the aquatic environment and that methylmercury is accumulated by fish and may present a hazard to human health. Consequently, this outbreak was the subject of intensive investigation resulting in an international conference in 1974 and many original publications in the scientific literature. 


\section{Routes of human exposure}

Although the chemical type of mercury was identified as methylmercury in all the specimens obtained from humans, whether blood or hair (Smith, Farris and Von Burg, 1976), other types of organo-mercury compounds were detected in the grain such as methoxypropyl-mercury and phenylmercury compounds (Jernelov, 1976). These latter 2 were the predominating fungicides in the barley which is used in Iraq mainly for animal feed whereas wheat is used for human consumption.

Soon after the outbreak it was clear that the main source of poisoning was the bread made from the treated wheat, yet it was important to prove that bread was the only source and to investigate other items of food.

Samples of different items of food such as rice, lentils, vegetables and fruits failed to show significant levels of mercury. It was of great concern to investigate the fate of the contaminated barley because of the marked disproportion between the amount distributed and the amount planted. Sheep, cattle and fowls are usually fed barley. However, estimation of organo-mercury in milk, meat and eggs indicated that these items were free of contamination.

Fish is not a common comestible in Iraq. Levels of mercury ranged between $0 \cdot 01-0 \cdot 15 \mathrm{mg} / \mathrm{kg}$. Figures of $0.3-0.5 \mathrm{mg} / \mathrm{kg}$ were found in a few fish caught near a caustic soda factory south of Baghdad.

Aquatic birds such as duck and waders contained relatively small amounts $(0.9-2 \cdot 7 \mu \mathrm{g} / \mathrm{g})$ and tail feathers of seed-eating birds contained $13 \cdot 5-21 \mu \mathrm{g} / \mathrm{g}$. High levels of mercury were found among dead seed-eating birds and rodents near the storehouses of seed where values of $15-40 \mu \mathrm{g} / \mathrm{g}$ were found in the muscles, and high levels were detected in the feathers. It was interesting to find that the leak of mercury from the grain stores was limited to the distance of about $200 \mathrm{~m}$. The mercury value dropped markedly after this distance and, at about $5 \mathrm{~km}$, birds and insects contained the same regional background values (Jernelov, 1976).

Mutton is the third item most frequently consumed by the Iraqi family after bread and rice. Because sheep and cattle were fed with treated barley and some of them succumbed in provinces where the distribution of seed was heavy, a nation-wide survey of the animal kingdom was planned. Analyses of muscle, kidneys and liver of sheep and cattle were made for one of every 100 animals slaughtered. Over 30000 analyses were made representing $>3$ million animals. Values $>0.5 \mu \mathrm{gHg} / \mathrm{g}$ of muscle were found in $2 \cdot 6-12 \%$ of the animals depending on how heavy the exposure was in different provinces. Thirty-four per cent. of the animal kidneys examined at the same time contained amounts $>0.5 \mu \mathrm{g} / \mathrm{g}$.
The percentage fell progressively over a period of 2 months so that only $4 \%$ of the meat and $12 \%$ of the kidneys contained values $>0.5 \mu \mathrm{g} / \mathrm{g}$. However, as an extra safety measure, all slaughter-houses were closed until this investigation was completed. Actually, the average individual consumption of meat in Iraq per day is so small that even on the unlikely assumption that a person happened to consume the meat which contained $0.5 \mu \mathrm{gHg} / \mathrm{g}$, daily intake of mercury would not be hazardous (Bakir et al., 1976b).

It is of interest to mention that the half-life of mercury was found to be shorter in sheep and cattle than in humans (Hilmi, 1977; Al-Rawi et al., 1978). Gastrointestinal symptoms in man were more pronounced than were neurological symptoms. This, the authors believe, is due to the different compounds used to treat barley, namely methoxypropylmercury and phenylmercury.

Evidence that home-made bread prepared from treated wheat was the predominant vehicle of exposure was supplied by analysis of samples of blood and the results of questionnaire surveys of consumption of contaminated bread. The background blood concentration in the unexposed rural population was less than $10 \mathrm{ngHg} / \mathrm{ml}$ for $99 \%$ of the samples tested. Individuals in large cities including policemen, military personnel, students, nurses, and people employed in a variety of industries, had blood concentrations of less than $20 \mathrm{ngHg} / \mathrm{ml}$ in $98 \%$ of the 300 individuals tested. In contrast, those who had consumed the contaminated bread had blood concentrations of mercury as high as $\mathbf{4 0 0 0}$ $\mathrm{ngHg} / \mathrm{ml}$. The correlation coefficient relating blood concentration to the amount of mercury ingested from bread was reported to be 0.9 . The amount of mercury ingested from bread was estimated from the average mercury content of the bread multiplied by the amount of bread consumed (Bakir et al., 1973). Methylmercury ingested by pregnant women passed to the fetus and methylmercury in lactating mothers was transferred to the suckling infant via the mother's milk (Bakir et al., 1973).

In conclusion, 3 major routes of human exposure were identified-the consumption of bread prepared from treated grain, the suckling of milk from exposed mothers, and pre-natal exposure. The clinical picture will be presented according to the age group corresponding to these 3 different routes of exposure.

\section{Pre-natal exposure group}

A rare opportunity was brought about during the long and devastating epidemic in that many of the victims were children and pregnant women (Bakir et al., 1973). Fifteen infant-mother pairs were studied by carrying out serial blood analyses for mercury together with repeated clinical examination with 
special attention to examination of the CNS since this was the target organ. Mercury passed freely through the placenta to such an extent that the infant's blood mercury level at birth was higher than the level in the mother's blood in most cases. This difference could not be accounted for by the higher haematocrit of the infant because it was a repeated observation over a few months and remained elevated after the appropriate correction was made for the haematocrit (Amin-Zaki et al., $1974 a, 1976$ ) since about $90 \%$ of mercury is present inside the red blood corpuscles. The 15 infants were examined between 6 days and 6.5 months of age; 11 of them were examined when they were less than 2 months of age. They had no difficulty in suckling or swallowing and had no congenital defects. None of them showed acrodynia. Six infants were found to be affected and 5 of these were severely so. Three of the infants had a head circumference less than the third centile for their age. Weight and length were not remarkable.

All of the 6 affected infants showed irritability and excessive crying. The mental power was severely affected in 4 infants. The muscle tone was increased and the reflexes were brisk. The Babinski's reflex was extensor in 12 infants and was not considered of itself to be significant. The abdominal and cremasteric reflexes were absent in a few. Sensory tests at this age are not easy but all infants responded to pinpricks.

Four infants were blind and vision was impaired in another. The fundi appeared normal except for pallor of the disc and narrowing of the vessels in one. The hearing was grossly impaired in 4.

Six of the mothers showed signs of poisoning which was similar to the picture seen in non-pregnant adults. Blood levels in some of the infants were alarmingly high. All infants with levels $>3000$ $\mathrm{ngHg} / \mathrm{ml}$ were severely affected. The lowest level seen among clinically affected infants was 564 parts $/ 10^{\circ}$. However, 7 infants with a blood mercury level of between 122-636 parts $/ 10^{9}$ had no signs or symptoms. It should be mentioned that the infant may have been exposed to a much higher level of methylmercury earlier during the exposure since the level reported was measured later in the study (Table 1).

Two mothers showed signs of poisoning while their infants were free; blood mercury levels were 416 and 602 parts $/ 10^{9}$ in the mothers; 636 and 476 parts $/ 10^{9}$ in the infants respectively.

Mercury was excreted in the milk in appreciable quantities, the coefficient is about $1: 10$ (Bakir et al., 1973; Amin-Zaki et al., 1976). Infants were exposed to a higher level of mercury and continued to have a higher level through breast feeding (Fig. 1).

Studies done at a later date (Marsh et al., 1977) showed undisputed abnormal neurological signs in children exposed to a lower mercury level. A significant number of children showed signs of early motor or mental retardation, delayed speech, extensor plantar response or other pathological neurological signs when the peak concentration of mercury in maternal hair was $>100$ parts $/ 10^{6}$. This would correspond to a peak maternal blood concentration during pregnancy of $400 \mathrm{ngHg} / \mathrm{ml}$.

Clinical observations among Iraqi children and mothers seem to be remarkably different from the Japanese (Harada, 1966). Japanese children suffered severe CNS damage while their mothers had little or none. In contrast, only 6 of 15 Iraqi infants

TABLE 1. Signs and symptoms of methylmercury in mothers (a) and their infants prenatally exposed

\begin{tabular}{|c|c|c|c|c|c|}
\hline \multirow{2}{*}{$\begin{array}{c}\text { Date of 1st } \\
\text { examination } \\
1972\end{array}$} & \multirow{2}{*}{$\begin{array}{c}\text { Trimester of } \\
\text { start of } \\
\text { exposure }\end{array}$} & \multicolumn{2}{|c|}{ Infants } & \multicolumn{2}{|c|}{ Mothers } \\
\hline & & $\begin{array}{c}\text { Blood } \\
\text { total } \mathrm{Hg} \mathrm{ng} / \mathrm{ml}\end{array}$ & $\begin{array}{l}\text { Signs and } \\
\text { symptoms }\end{array}$ & $\begin{array}{c}\text { Bloodb } \\
\text { total } \mathrm{Hg} \mathrm{ng} / \mathrm{ml}\end{array}$ & $\begin{array}{l}\text { Signs and } \\
\text { symptoms }\end{array}$ \\
\hline $6 / 3$ & 3 & 4220 & Yes & 2390 & Yes \\
\hline $11 / 4$ & 3 & 3190 & Yes & 1505 & Yes \\
\hline $11 / 4$ & 3 & 3190 & Yes & 1083 & Yes \\
\hline $18 / 4$ & 3 & 200 & No & 40 & No \\
\hline $9 / 5$ & 3 & 162 & NA & 97 & No \\
\hline $1 / 6$ & 2 & 387 & No & 253 & No \\
\hline $1 / 6$ & 2 & 636 & No & 416 & Yes \\
\hline $1 / 6$ & 2 & 122 & No & 187 & No \\
\hline $15 / 7$ & 3 & 476 & No & 602 & Yes \\
\hline $25 / 7$ & 1 & 284 & No & 170 & No \\
\hline $1 / 8$ & 1 & NA & No & 5 & No \\
\hline $6 / 8$ & 3 & 1053 & Yes & 173 & NA \\
\hline $7 / 8$ & 2 & 18 & No & 300 & Yes \\
\hline $8 / 8$ & 1 & 564 & Yes & 180 & No \\
\hline $14 / 11$ & 1 & 290 & No & 37 & No \\
\hline
\end{tabular}

a Adapted from Tables II and III of Amin-Zaki et al., 1974a.

b Blood samples were collected at time of the first examination. 
showed evidence of poisoning and only one mother was free of symptoms while her infant was affected. Blindness, irritability and crying were not observed among 22 Japanese subjects. Harada (1966) and Murakami (1972) noted difficulty with mastication and swallowing which was not observed among infants in the Iraqi epidemic. Some of the differences in these 2 series may have been due to the age of the subjects at the time of the examination. In Japan, they were examined at a more advanced age, when they were between one and 7 years old. Another explanation is that the Japanese victims were exposed for a longer period, through eating fish; while the Iraqi and other outbreaks were caused by fungicide poisoning (Harada, 1966; Murakami, 1972; Amin-Zaki et al., 1974a; Pierce et al., 1972).

It is difficult to determine what is the most hazardous period in the intra-uterine exposure since the number of infant-mother pairs is small and there are so many variables, such as the duration of the exposure, the amount ingested, the general health of the mother, the difference in half-life and other unknown factors. However, the data in Table 1 clearly indicate that exposure in the third trimester can lead to pre-natal damage.

\section{Exposure through suckling}

Amin-Zaki et al. (1974b) reported that at least 8 infants, who were exposed to mercury only through suckling, had blood mercury levels of about 200 $\mathrm{ng} / \mathrm{ml}$, which is the minimum toxic dose set for adults by a Swedish Expert Committee (Berglund et al., 1971). None of these 8 infants had any sign of poisoning (Fig. 3). The lack of signs among this group was rather surprising. It is possible that signs may appear during later life or that mercury ingested in maternal milk is in a less toxic form.

\section{Exposure from home-made bread}

The clinical picture among children and adults did not vary appreciably. The symptoms and signs appeared after a latent period which varied between one and 2 months but it could be as short as 15 days or as long as 100 days after the consumption of the home-made bread. The causes of individual variation in the length of the latent period is unknown although the individual variations in the half-life might play a role (Shahristani and Shihab, 1974; Greenwood et al., 1978).

For practical reasons patients were grouped in 3 main clinical categories: the mildly, the moderately, and the severely affected. The group which had been exposed and showed no evidence of poisoningthe asymptomatic, did not constitute a clinical group. Classification of individual patients was wholly on clinical grounds without the knowledge of blood mercury level. In the mild group, subjective symptoms predominated which were irritability, malaise, headache, generalized aches and pain, muscle weakness, abdominal discomfort and paraesthesiae, the latter being mainly circumoral and in the distal parts of the extremities. The moderate group exhibited, in addition to symptoms, cerebellar signs in the form of ataxia, dysarthria, tremor and upper motor neuronal lesions as reflected by changes in muscular tone, hyper-reflexia and positive Babinski's response. The 'severe' group also had visual disturbances and impairment of hearing. The ataxia was gross and the sensorium cloudy. Some of them were very severely affected. They were completely blind, deaf, dysphagic, and in pain, with persistence of primitive reflexes. Ultimately, coma and death might ensue. There was overlap between the categories but it has been shown that the number of patients found in each category is related, on a group basis, to the blood concentration of mercury (Amin-Zaki et al., 1978, 1979; Greenwood et al., 1978; Shahristani, Shihab and Al-Haddad, 1976).

The onset was insidious and progressive in all patients. However, it may be helpful to discuss in detail some of the salient clinical features. Since methylmercury is one of the more potent neurotoxic substances, the nervous system is the target organ

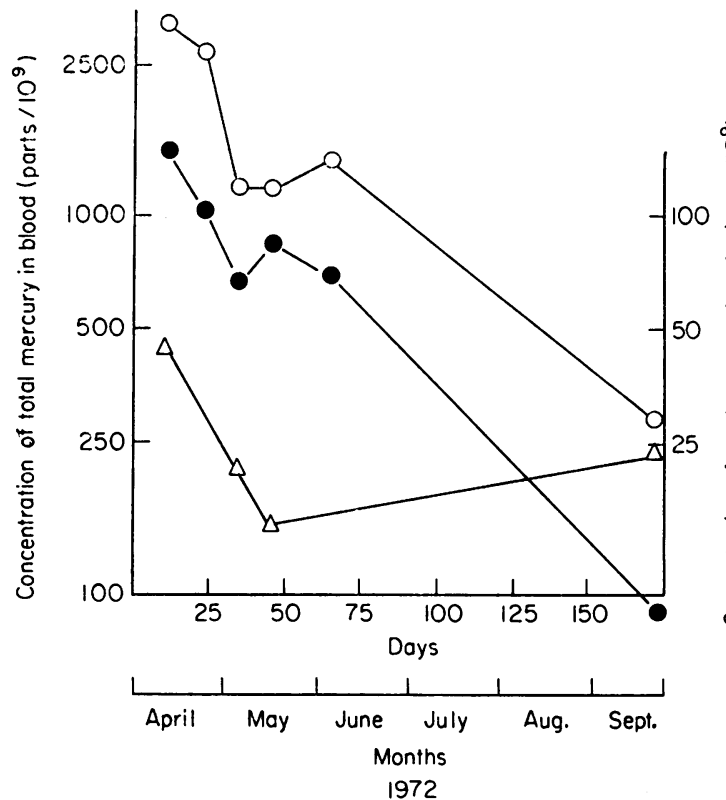

Fig. 1. The concentration of total mercury in infant blood $(O)$ and in maternal blood $(O)$ and milk $(\triangle)$ during April to September 1972. The approximate date of birth was 11 February, 1972. (From Fig. 2 of AminZaki et al., 1974a, by permission of the editor of Pediatrics.) 
affected. This affection is summarized under the following headings:

\section{The sensory system}

The symptoms were frequent and early in appearance. The background figure of people complaining of paraesthesia was about 5-10 in non-exposed rural areas while a positive answer for the same complaint was obtained in about $88 \%$ in people of heavily exposed areas (Kazantzis et al., 1976). High figures were also seen in hospital patients (Al-Damluji et al., 1976). This sensory change was mainly a feeling of pins and needles, numbness, 'insects moving under the skin' or, sometimes, burning. It is mainly peri-oral or glove and stocking in distribution but asymmetrical distribution was also reported. Some patients complained of a metallic taste in the mouth and sore gums.

On physical examination, sensitivity to pinpricks and touch could be detected. The 2-point discrimination was impaired, astereognosis was present in some and it was the only finding in 2 out of 19 patients. Sense of vibration and temperature was intact (LeQuesne, Damluji and Rustam, 1974).

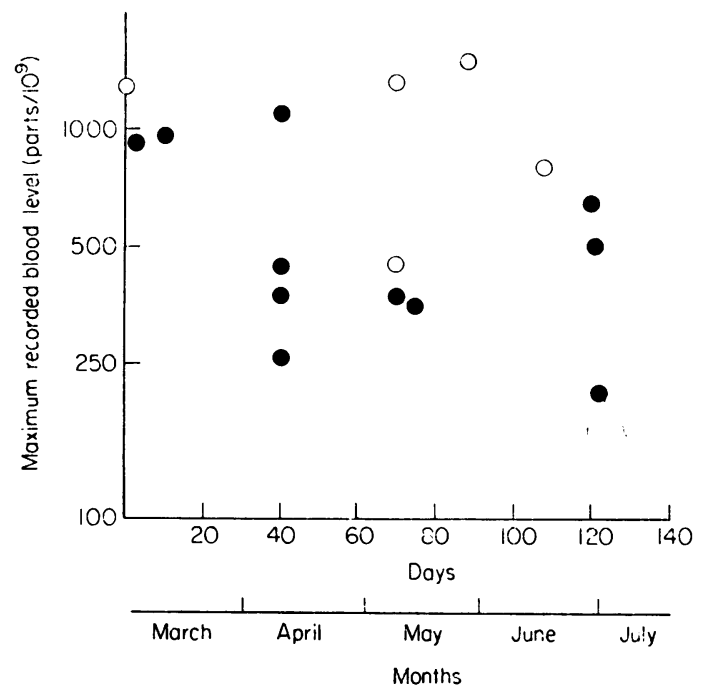

FIG. 2. The maximum recorded concentration of the total mercury in each infant's blood is plotted according to the date on which the sample was collected; this does not necessarily indicate the true maximum level in infants' blood. exposure only from milk; $\bigcirc$, exposure from milk and possibly from contaminated bread. (From Fig. 3 of Amin-Zaki et al., 1974b, by permission of the editor of Journal of Pediatrics.)

Sensory affection in mercury poisoning was considered for a long time as a peripheral neuropathy with little objective evidence (Hunter, Bomsford and Russell, 1940; Tekeuchi, 1972).
Detailed electrophysiological studies during the Iraq epidemic failed to find evidence for peripheral nerve affections. The sensory, motor velocity, the sensory threshold and $\mathrm{H}$ reflex gave negative results (LeQuesne et al., 1974; Von Burg and Rustam, 1974). These examinations were done 4 to 7 months after admission to hospital and patients were still symptomatic during the first examination. These negative findings, in addition to finding astereognosis as the sole finding, make peripheral neuropathy an unlikely cause and may point to a central, probably mid-brain origin.

A clinical picture similar to myasthenia gravis, with good response to prostigmine, was detected in $14 \%$ of the patients examined indicating interference with myoneural transmission (Von Burg and

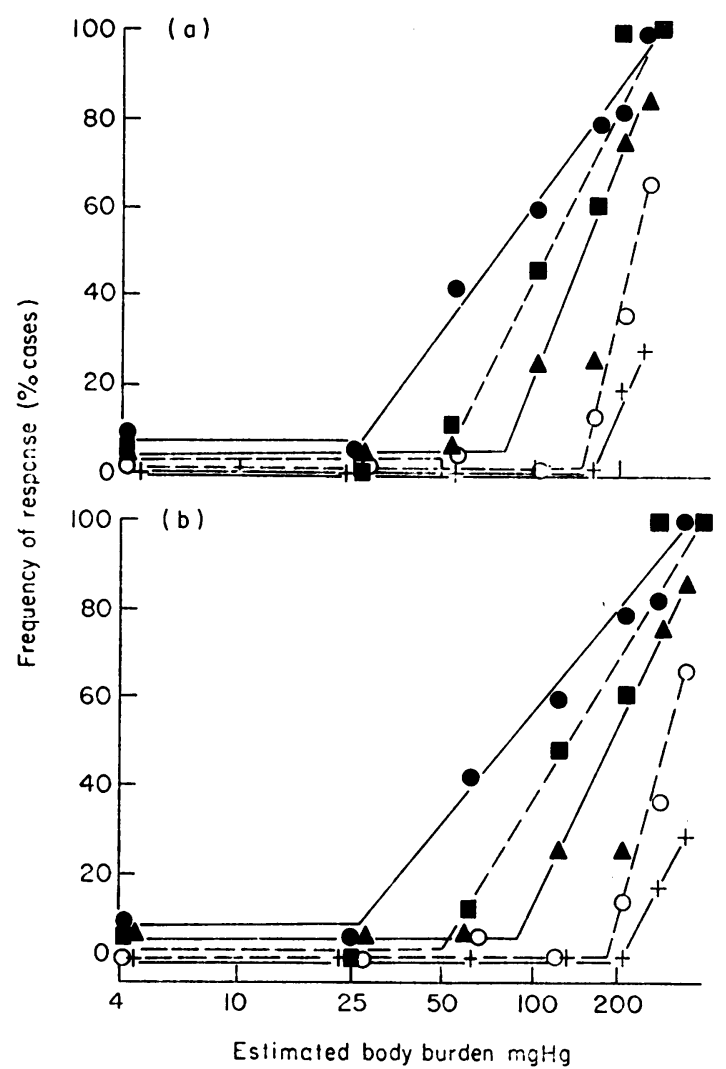

FIG. 3. The relationship between frequency of signs and symptoms and the estimated body burden of methylmercury; (a) at the time of onset of symptoms; (b) at the time of cessation of ingestion of methylmercury in bread. Both scales on the abscissa are for body burdens of methylmercury. The 2 scales result from different methods by which the body burden was calculated. (From Fig. 6 of Bakir et al., 1973, by permission of the editor of Science.) Paraesthesia, ataxia, $\Delta$ dysarthria, $\bigcirc$ deafness, + death. 
Rustam, 1974). Experiments on animals have confirmed these findings and have indicated that methylmercury inactivates the acetylcholine receptor at the myoneural junction (Von Burg and Landry, 1976; Shamoo, 1976).

\section{The motor system}

Large numbers of patients in the moderate and severe group complained of weakness such as 'my legs or arms do not obey me' or 'can't help me'. Paresis was frequent but paralysis was seen only in the severe group. The muscle tone was increased more often than decreased (Al-Damluji et al., 1976).

Muscle wasting was evident in the paralysed and bedridden patients. The tendon reflexes were not constant. Increased muscle tone was observed in the majority and clonus could sometimes be elicited. Hyporeflexia or no response was occasionally noted (Kazantzis et al., 1976; Al-Damluji et al., 1976; Hunter, Bomsford and Russell, 1940; Takeuchi, 1972). Extensor Babinski's reflex was frequently present.

\section{Abnormal movement}

Besides the tremor which is not usual, jerky myoclonic and choreo-athetotic movements were rarely seen in adults and children. The autonomic nervous system also had its share of involvement, shown by the loss of sphincter control in 13 children and 11 adults. Salivation was frequent and lacrimation occasional, priapism occurred in 4 children out of 40 examined (Amin-Zaki et al., 1978).

\section{Cerebellar involvement}

This was frequent. Early complaints of unsteadiness and frequent falls were common. It is possible that the motor affection and the ataxia are contributing factors. Intention tremor and Romberg's sign were often present and walking on straight lines was often impaired. In the more severely affected patients assistance and support were needed to sit or stand. The severe cases were completely ataxic, bedridden and beyond help.

\section{Special senses and higher functions \\ Vision}

Abnormalities in $>50 \%$ of the patients varied from slight restrictions of the field to tunnel vision and complete blindness. Fundoscopy showed relatively less changes than expected. Papillitis was seen in $>10$ cases. Pallor of the disc was seen occasionally and optic atrophy, either bilateral or unilateral, was found in very few. The retinal vessels were diminished and constricted in some cases (Sabelaish and Hilmi, 1976; Rustam and Hamdi, 1974).

\section{Hearing}

Impaired hearing to complete deafness was seen in $>33 \%$ of the affected adults (Al-Damluji et al., 1976) and in $>50 \%$ of affected children (AminZaki et al., 1978). Some of the patients complained of tinnitus or abnormal noises.

\section{Speech}

All shades of dysarthria were seen, depending on the severity of poisoning, from the slow scanning speech or the slurred, partly intelligible, to the explosive type, a word or two at a time, completely unintelligible. In the very severe, the occasional cry as if the affected person was in very severe pain, was all that a patient could produce.

Abnormalities of smell and taste were rare and were noted as a metallic taste or burning sensation in the mouth. A blue line on the gum was not seen in any of the cases of poisoning.

\section{Mental features}

The mental powers of all ages were affected in varying severity depending on the degree of poisoning. The mild and moderately poisoned remained conscious with clouded memory, impaired sensorium, and were stuporose; the very severely poisoned showed decerebrate and decorticate features more like kinetic mutism than coma.

\section{The psychiatric picture}

In the mildly poisoned, one could see anxiety and fear of death. Among other grades of poisoning, depression was frequent; insomnia and forgetfulness were common (Magazaji, 1974). It is difficult to speculate how much of a patient's psychiatric behaviour is due to the poisoning and how much is due to the circumstances surrounding a tragedy such as disability or death in the patient's family and friends.

\section{Pregnant women}

Some of the women aborted; and in 5 deliveries there was prolonged labour which had not been noted in their earlier pregnancies. This could have been due to abdominal muscle weakness. Of 31 pregnant women, $14(45 \%)$ died from unexplained causes (Bakir et al., 1973).

\section{Dose-response}

The degree of clinical severity correlated well with blood and hair mercury concentrations (AminZaki et al., 1978, 1979; Shahristani et al., 1976). Severe cases usually showed levels $>2000 \mathrm{ngHg} / \mathrm{ml}$, while the mild usually had lower levels, but for 
individual symptoms or signs, the relationship was inconstant.

Blood samples were collected 2 to 3 months after the appearance of symptoms. Levels $>200 \mathrm{ngHg} / \mathrm{ml}$ were not usually associated with symptoms. In children, higher levels exist without positive clinical manifestations (Amin-Zaki et al., 1978).

The closest correlation was found between the frequency of specific symptoms and the total calculated amount of mercury ingested (Fig. 3). The lowest burden of mercury noted was $0 \cdot 5-0 \cdot 8$ $\mathrm{mg} / \mathrm{kg}$ body weight for the early symptoms of paraesthesia. Ataxia, dysarthria and deafness followed with increasing total body burden. These figures were estimated as the point of intersection of a horizontal line (representing the background frequency of signs and symptoms in the non-exposed rural population) and the line connecting those groups having elevated frequency due to methylmercury exposure. The authors were aware that there are alternative methods for calculating the body burden of mercury when the effects become detectable (Nordberg and Strangert, 1976).

Infants and children seem to have a higher tolerance to post-natal exposure but careful and long follow-up may reveal signs which appear with lower mercury levels (Amin-Zaki et al., 1974b, 1978).

The slope of the lines in Fig. 3 relating frequency of signs and symptoms to body burden of methylmercury indicate wide individual variation. For example, a sensitive individual may complain of paraesthesiae at a body burden of $25-40 \mathrm{mgHg}$ but a resistant person may tolerate a body burden of over $200 \mathrm{mg}$ without any ill effect. The reasons for this wide variation are not known. Some methodological errors in calculating the body burden may have contributed (Bakir et al., 1973). Individual differences in half-life may also have contributed.

\section{Investigation}

In spite of the very wide range of laboratory investigations, all the biochemical data concerning liver and kidney functions were normal. The haematological results were negative except for eosinophilia in the peripheral blood which could not be put down to other causes. The cerebrospinal fluid showed no abnormalities besides containing $6 \%$ of the total mercury of the blood. Different proportions of the mercury were also found in milk, urine, amniotic fluid and in the vitreous humour. Electrocardiographic tracing showed non-specific RST T-wave changes in about $20 \%$ of the cases (Murtadha, 1979) which is less than and different from the earlier outbreak of mercury poisoning in Iraq. The reason for this difference may lie in the fact that the mercurial compound was different in the earlier outbreak (Jalali and Abbasi, 1961; Dahan and Orfali, 1964).

Cytological studies of poisoned patients showed an increase in the chromosomal aberration in the lymphocytes but this was not statistically significant (Farman, 1974).

\section{Histopathology and tissue mercury content}

The main histopathological changes were in the CNS. The leptomeninges were turbid. Small foci of cystic changes were found in the grey matter and the basal ganglion. On microscopy, degeneration, complete loss of neurones with hyperplasia of the astrocytes were found in all layers of the cortex including the cerebellum and cerebrum. The Purkinje basket cells were less affected than granular cells. The degenerative changes were patchy (AlSaleem et al., 1976). Pathological changes were proportional to the degree of poisoning and mercury blood level. In general, the findings in the Iraqi cases were similar to those described by Takeuchi (1972) in Minamata disease. The average mercury level in the liver was lower than in the Japanese cases (Magos et al., 1976).

In stillborn infants the nerve cells are either poorly developed or completely absent and replaced by astrocyte or microglial proliferation. Studies done by Choi and his associates on the brains of 2 infants exposed to mercury showed incomplete or abnormal migration of the neurones. The effect is selective, the nature of the lesion in the infant is faulty development rather than a destructive lesion as in the adult, which may point to a higher vulnerability of the infant's CNS (Choi et al., 1977).

\section{Treatment}

Not all patients received treatment because of the limited availability of the necessary drug. In most cases the clinical picture was well established before the drug became available. D-Penicillamine and $N$-acetyl-D-L-penicillamine were used in a daily dose of one $\mathrm{g}$ for 10 to 14 days. The course was repeated for a second or third time in some cases. There was an initial small rise in mercury blood level followed by a lowering. The reduction in the blood level varied from 8 to $48 \%$. One of the reasons for this variation was that the dose was not calculated on body weight basis. A dose of $2 \mathrm{~g}$ /day was used in some and was found to be more effective than one g/day for lowering mercury levels. Intramuscular doses of 2,3-dimercaptopropane sulphonate were given at the rate of $50 \mathrm{mg} / 10 \mathrm{~kg}$ body weight thrice the 1st day, twice the 2nd day, and thence once/day until day 7 . This agent produced a more constant reduction in the mercury blood level to $20-30 \%$. An increase in urinary excretion of mercury was observed with all agents tested. The patients were 
observed in a hospital for a period of 4 to 8 weeks and, in some, this period exceeded 100 days. The present authors found that mild and moderate cases improved whether they received treatment or not (Bakir et al., 1976a). Some of the severe cases improved and some deteriorated, regardless of the treatment. In those who improved clinically, the improvement did not correspond to the reduction of the blood mercury level. Similar observation was made in the psychiatric findings (Magazaji, 1974). Continuous administration of chelating agents for 25 days did not result in more appreciable clinical improvement.

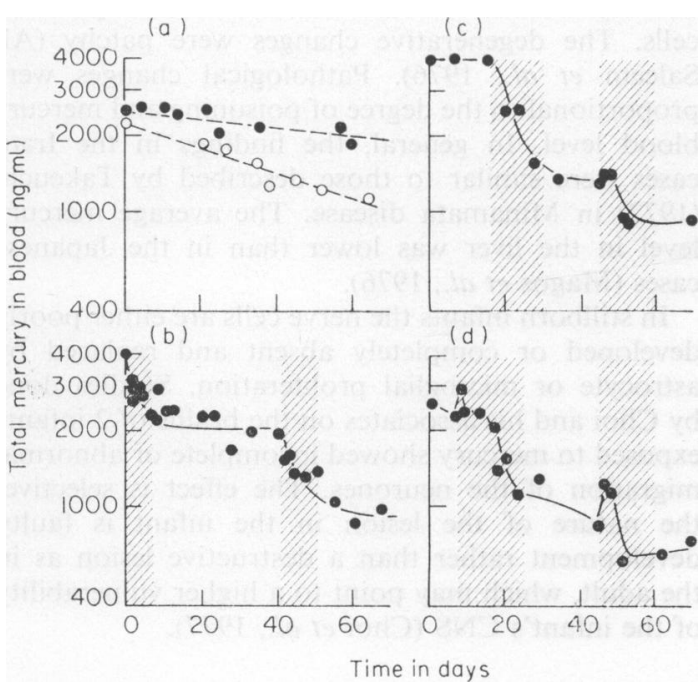

Fig. 4. The clearance of mercury from blood. (a) Control patients not treated with mercury-chelating agents. , A 10-year-old boy, $28 \mathrm{~kg}$ body weight; $O$, a 6-year-old boy, $20 \mathrm{~kg}$. (b-d) Patients treated with mercury-chelating agents. The hatched areas indicate the treatment period. (b) Treatment with thiol resin. During the first treatment period, $40 \mathrm{mg} / \mathrm{kg}$ was administered once each day; during the second treatment period, the amount given was $160 \mathrm{mg} / \mathrm{kg} /$ day (a 13-year-old girl, $28 \mathrm{~kg}$ body weight). (c) Treatment with D-penicillamine. The dosage during both treatment periods was $40 \mathrm{mg} / \mathrm{kg} /$ day (a 4-year-old boy, $16 \mathrm{~kg}$ body weight). (d) Treatment with $N$-acetyl-D-L-penicillamine. The dosage during both treatment periods was $40 \mathrm{mg} / \mathrm{kg} /$ day (a 5-year-old girl, $18 \mathrm{~kg}$ body weight). (From Fig. 4 of Bakir et al. (1973) by permission of the editor of Science).

\section{Thiol resin}

It was the first time that this agent was used to treat humans. The treatment was based on prior observations in animals that methylmercury is secreted in bile and reabsorbed in the lower intestine. An oral dose of a non-absorbable mercury binding resin trapped the mercury secreted in the bile, thus preventing its subsequent reabsorption and thereby greatly enhancing its faecal excretion (Norseth and Clarkson, 1971 ; Clarkson, Small and Norseth, 1973). The resin was given in doses of $8 \mathrm{~g} /$ day by mouth for intermittent periods. It lowered mercury levels markedly (Fig. 4). No side effects were observed with any of the drugs used.

It is thought that an earlier initiation of treatment after exposure and before development of signs of organic lesion would be more likely to prevent the development of serious damage to the CNS.

\section{Haemodialysis}

After successful animal experiments, this procedure was used for treating 2 patients (Abbasi, Kostyniak and Clarkson, 1974; Kostyniak et al., 1975; Kostyniak, Clarkson and Abbasi, 1977; Abbasi, Kostyniak and Clarkson, 1978). Methylmercury was converted to a diffusible substance by adding L-cysteine (a chelating agent of low molecular weight) into the arterial blood entering the dialyser. The returning blood to the patient contained reduced amounts of mercury and also of the chelating agent. Data indicated reduction in the mercury content of the extravascular compartment. The calculated decline in the body burden was as much as $\mathbf{1 0}$ times greater than any method described. The 2 patients improved clinically but it is difficult to tell how much of this improvement was contributed by the natural course of the disease and how much by the haemodialysis, since this was started late after the onset (Abbasi et al., 1974, 1978).

\section{Treatment by exchange transfusion}

This was attempted in 3 children (6 months, 13 months and 10 years of age). The average amount removed was estimated to be $6 \%$ of the body burden as compared with the $1 \%$ in $24 \mathrm{hr}$ by natural excretory channels. Other mercury-containing tissues were also cleared besides the blood. Two children were severely affected and the third one had a high blood level of mercury. Some improvement in the motor function and power was noticed on follow-up. It is possible that early treatment may prevent further damage to the nervous system (Elhassani et al., 1978).

\section{Progress and course}

Exposure and the amount of mercury ingested varied a great deal among intoxicated people and obviously this affected the outcome. It is a general observation by many observers that improvement took place in the mild and moderate cases (Kazantzis et al., 1976; Al-Damluji et al., 1976; Amin-Zaki et al., 1978). 
Sometimes the improvement was impressive (Kazantzis et al., 1976). The earliest symptom to disappear was paraesthesia which was also the first to appear. Some patients who had been bedridden started to walk. There was improvement in vision and speech and a gain in motor power. Improvement was also observed among some of the severe cases. Improvement was inversely proportional to the degree of poisoning and damage. The improvement came with the lapse of time aided by personal effort and rehabilitation. Children showed more improvement probably because their systems were not yet affected by factors such as ageing and atherosclerosis. A more striking clinical improvement was seen in Iraq than in Japan. One explanation is that Iraqi patients were exposed acutely for a short period of one to 2 months, while the Japanese were exposed for several months or years (Katsuma, 1968; Tsuchiya, 1969).

A second observation was made 6 months later on a group of 77 patients by the same observers without reference to their earlier findings. The clinical diagnostic category did not change in $67 \%$, deteriorated in $8 \%$ and improved in $22 \%$ (13 of the 17 patients had symptoms when first seen). Diagnosis was indeterminate in the remaining 3\% (Kazantzis et al., 1976). The high mortality of 459 cases out of 6530 reported hospital cases reflects the severity of affection and exposure. The severe and very severely affected cases did not improve and the neurological signs persisted.

\section{Conclusion}

The tragic consequences in Iraq and in other countries, resulting from the use of mercurycontaining fungicides, should be a clear warning to all authorities to avoid such fungicides and to seek those that are safe. If an episode of poisoning occurs, the government should mobilize all its resources and establish a scientific group to deal with the situation. All possible technical aid should be sought from international bodies such as the World Health Organization, academic institutions, and individual experts. The possible sources of intoxication should be identified to prevent further human exposure. An expert chemical/medical team should be formed to examine and follow the cases and to institute a regime of treatment and rehabilitation.

Drugs should be available wherever these may give the only possible chance to prevent serious permanent damage to patients. Treatment should be as early as possible. Continuous administration of the chelating agents such as penicillamine should be used at doses as high as the patient will tolerate. Other potentially useful approaches involve the thiol resin exchange transfusion and haemodialysis.

\section{Acknowledgments}

The authors, in collaboration with the Scientific Committee of the Medical College (F. Bakir, Chairman; A. Al-Khalidi, Secretary; S. F. Al-Damluji; W. Al-Mufti; N. A. Al-Rawi; H. Shiristani; H. Dhair), would like to extend their deep thanks and appreciation to Professor $T$ W. Clarkson and Dr D. Marsh (University of Rochester Medical Center, Rochester, New York) for their invaluable help, and in reviewing and editing this article. They also thank Mrs Klein for her help in preparing the manuscript.

\section{References}

Abbasi, A.H., Kostyniak, P. $Z$ Clarkson, T.W. (1974) Extracorporeal regional complexation dialysis in patients with mercury poisoning. WHO Conference on Intoxication due to Alkylmercury-Treated Seed, Baghdad, Iraq.

Abbasi, A.H. Kostyniak, P. \& Clarkson, T.W. (1978) An extracorporeal complexing hemodialysis system for the treatment of methylmercury poisoning. III. Clinical applications. Journal of Pharmacology and Experimental Therapeutics, 207 (1), 249.

Al-Damluji, S.F. \& The Clinical Committee on Mercury PoIsonING (1976) Intoxication due to alkylmercurytreated seed-1971-1972 outbreak in Iraq: clinical aspects. Bulletin of the World Health Organization, 53 (Suppl.), 65.

Al-RaWI, N., Al-Abrahim, Khalidi, A., Kadauri, A. \& The ScIENTIFIC COMMITTEe (1978) Mercury poisoning in sheep. Iraqi Medical Journal, 26 (1/2), 53.

Al-Saleem, T. \& Clinical Committee on Mercury PoIsoning (1976) Levels of mercury and pathological changes in patients with organomercury poisoning. Bulletin of the World Health Organization, 53 (Suppl.), 99.

Al-Shahristani, H. \& Shihar, K. (1974) Variation of biological half-life of methylmercury in man. Archives of Environmental Health, 28, 342.

Amin-Zaki, L., Elhassani, S., Majeed, M.A., Clarkson, T.W., DOHERTY, R.A. \& GReENWOOD, M.R. (1974a) Intrauterine methylmercury poisoning in Iraq. Pediatrics, 54, 5, 587.

Amin-Zaki, L., Elhassani, S., Majeed, M.A., Clarkson, T.W., DOHERTY, R.A. \& GReENWOOD, M.R. (1974b) Studies of infants postnatally exposed to methylmercury. Journal of Pediatrics, 85, 1, 81.

Amin-Zaki, L., Elhassani, S., Majeed, M.A., Clarkson, T.W., DoherTy, R.W., Greenwood, M.R. \& GiovanoliJAKUBCZAK, T. (1976) Perinatal methylmercury poisoning in Iraq. American Journal of Diseases of Children, 130, 1070.

Amin-Zaki, L., Majeed, M.A., Clarkson, T.W. \& GreenwooD, M.R. (1978) Methylmercury poisoning in Iraqi children. Clinical observations over two years. British Medical Journal, 1, 613.

Amin-Zaki, L., Majeed, M.A., Elhassani, S.B., Clarkson, T.W., Greenwood, M.R. \& DoherTy, R. (1979) Prenatal methylmercury poisoning. Clinical observations over five years. American Journal of Diseases of Children, 133, 172.

Bakir, F., Al-Khalidi, A., Clarkson, T.W. \& Greenwood, M.R. (1976a) Clinical observations on treatment of alkylmercury poisoning in hospital patients. Bulletin of the World Health Organization, 53 (Suppl.), 87.

Bakir, F., Al-Shahristani, Al-Rawi, N.Y., Khadouri, A. \& AL-MUFTI, W. (1976b) Indirect sources of mercury poisoning in the Iraq epidemic. Bulletin of the World Health Organization, 53 (Suppl.), 129.

Bakir, F., Damluji, S.F., Amin-Zaki, L., Murtadha, M., Khalidi, A., Al-Rawi, N.Y., Tikriti, S., DhahIR, H.I., Clarkson, T.W., Smith, J.C. \& Doherty, R.A. (1973) Methylmercury poisoning in Iraq. Science, 181, 230.

Berglund, F., Berlin, M., Birke, G., Cederlof, R., von Euler, U., FriberG, L., HOMSTEdT, B., JonsSON, B., 
Luning, K.G., Ramel, C., Skerfying, S., Swensson, A. \& Tejning, S. (1971) Methylmercury in fish. Nordisk hygienisk tidskrift, Suppl. 4.

Choi, B.H., Lapham, L.W., Amin-Zaki, L. \& Saleem, T. (1978) Abnormal neuronal migration, deranged cerebral cortical organization, and diffuse white matter astrocylosis of human fetal brain. A major effect of methylmercury poisoning in utero. Journal of Neuropathology and Experimental Neurologv, 37 (6), 719.

Clarkson, T.W., Small, H. \& Norseth, T. (1973) Excretion and absorption of methylmercury after polythiol resin treatment. Archives of Environmental Health, 26, 173.

DahaN, S.S. \& ORfali, H. (1964) Electrocardiographic changes in mercury poisoning. American Journal of Cardiology 14, 178.

Elhassani, S.B., Amin-Zaki, L., Majeed, M.A., Clarkson, T.W., Doherty, R.A., GreenWoOd, M.R. \& KilpPer, R.W. (1978) Exchange transfusion treatment of methylmercury-poisoned children. Environmental Health Sciences, $13,63$.

FARMAN, N. (1974) Chromosomal studies in methylmercury poisoning. WHO Conference on Intoxication due to Alkylmercury Treated Seed, Baghdad, Iraq.

Greenwood, M.R., Clarkson, T.W., Doherty, R.A., Gates, A.H., Amin-Zaki, L., Elhassani, S. \& Majeed, M.A. (1978) Blood clearance half-times in lactating and non-lactating members of a population exposed to methylmercury. Environmental Research, 16, 48.

HARADA, Y. (1966) Study group on Minamata disease. In: Minamata Disease (Ed. by Katsuma, M.). Pp. 93, Kumamoto University, Japan.

HILMI, M. (1977) Distribution and excretion of methyl mercury in sheep. Thesis for M.S. degree, College of Pharmacy, University of Baghdad, Iraq.

Hunter, D., Bomsford, R. \& Russell, D. (1940 Poisoning by methylmercury compound. Quarterly Journal of Medicine, 9, 193.

Jalali, M.A. \& ABbasI, A.H. (1961) Poisoning by ethylmercury toluene sulphonanlide. British Journal of Industrial Medicine, 18, 303.

JERNELOV, A. (1976) Environmental contamination by mercury in Iraq. Bulletin of the World Health Organization, 53 (Suppl.), 115.

Katsuma, M. (1968) Minimata Disease. Study Group of Minamata disease. Kumamoto University, Japan.

Kazantzis, G., Al-Mufti, A.W., Copplestone, J.F., Majeed, M.A. \& MAHMoud, R.M. (1976) Epidemiology of organomercury poisoning in Iraq: III. Clinical features and their changes with time. Bulletin of the World Health Organization, 53 (Suppl.), 49.

Kostyniak, P.J., Clarkson, T.W. \& Abbasi, A.H. (1977) An extracorporeal complexing hemodialysis system for the treatment of methylmercury poisoning. II. In vivo applications in the dog. Journal of Pharmacology and Experimental Therapeutics, 203, 253.

Kostyniak, P.J., Clarkson, T.W., Cestero, R.V., Freeman, R.B. \& AbBASI, A.H. (1975) An extracorporeal complexing hemodialysis system for the treatment of methylmercury poisoning. I. In vitro studies of the effects of four complexing agents on the distribution and dialysability of methylmercury in human blood. Journal of Pharmacology and Experimental Therapeutics, 192, 260.

LeQuesne, P.M., Damluji, S. \& Rustam, H. (1974) Electrophysiologic studies of peripheral nerves in patients with organic mercury poisoning. Journal of Neurology, Neurosurgery and Psychiatry, 37, 333.
Magazaji, H.I. (1974) Psychiatric aspects of methylmercury poisoning. Journal of Neurology, Neurosurgery and Psychiatry, 37, 954.

Magos, L., Bakir, F., Clarkson, T.W., Al-Jawad, A.M. \& AL-Soffi, M.H. (1976) Tissue levels of mercury in autopsy specimens of liver and kidney. Bulletin of the World Health Organization, 53 (Suppl.), 93.

Marsh, D.O., Myers, G.J., Clarkson, T.W., Amin-ZaKi, L. \& TIKRITI, S. (1977) Fetal methylmercury poisoning: New data on clinical and toxicological aspects. Transactions of the American Neurological Association, 102, 69.

Murakami, U. (1972) The effect of organic mercury on intra-uterine life. Advances in Experimental Medicine and Biology, 27, 301.

Nordberg, G.F. \& Strangert, P. (1976) Estimations of a dose-response curve for long-term exposure to methylmercuric compounds in human beings taking into account variability of critical organ concentration and biological half-time: A preliminary communication. In: Effects and Dose-response Relationships of Toxic Metals. (Ed. by Nordberg, G.F.) Elsevier Scientific Publishing Co., Amsterdam.

NoRSETH, T. \& Clarkson, T.W. (1971) Intestinal transport of ${ }^{203} \mathrm{Hg}$-labelled methyl mercury chloride. Archives of Environmental Health, 22, 568.

Pierce, P.E., Thompson, J.F., Likosky, W.H., Nickey, L.N., Barthal, W.F. \& Hinman, A.R. (1972) Alkylmercury poisoning in humans: Report of an outbreak. Journal of the American Medical Association, 220, 1439.

RustaM, H. \& HAMDI, T. (1974) Methyl mercury poisoning in Iraq. A neurological study. Brain, 97, 499.

Sabelaish, S. \& Hilmi, G. (1976) Ocular manifestations of mercury poisoning. Bulletin of the World Health Organization, 53 (Suppl.), 83.

Shahristani, H. \& Shihab, K. (1974) Variation of biological half-life of methylmercury in man. Archives of Environmental Health, 28, 342.

Shahristani, H., Shihab, K. \& Al-Haddad, I.K. (1976) Mercury in hair as an indicator of body burden. Bulletin of the World Health Organization, 53 (Suppl.), 105.

Shamoo, A.E. (1976) Differential effects of mercurial compounds on excitable tissue. Chemico-Biological Interactions, $12,41$.

Smith, J.C., Farris, F.F. \& Von Burg, R. (1976) Chemical type of mercury in patients in the outbreak of organomercury poisoning in Iraq. Bulletin of the World Health Organization, 53 (Suppl.), 61.

TAKeUCHI, T. (1972) Biological reactions and pathological changes in human beings and animals caused by organic mercury contamination. In: Environmental Mercury Contamination (Ed. by Hartung, R. and Dinman, B.D.). Pp. 247, Ann Arbor Science Publishers Inc., Ann Arbor, Michigan.

TsuchiYA, A. (1969) Epidemic of mercury poisoning in the Agano River area-an introductory review. Keio Journal of Medicine, 18, 213.

VON BURG, R. \& LANDRY, T. (1976) Methylmercury and the skeletal muscle receptor. Journal of Pharmacy and Pharmacology, 28, 548 .

Von Burg, R. \& Rustam, H. (1974) Electrophysiological investigation of methylmercury intoxication in humans. Evaluation of peripheral nerve by conduction velocity and electromyography. Electroencephalography and Clinical Neurophysiology, 37, 381 . 